Thorax, 1980, 35, 725-732

\title{
Response to methotrexate in fibrosing alveolitis associated with connective tissue disease
}

\author{
D G I SCOTT AND P A BACON
}

From the Royal National Hospital for Rheumatic Diseases, Bath

ABSTRACT Methotrexate by intermittent intramuscular injection was used to treat three patients with fibrosing alveolitis complicating connective tissue diseases. All three patients had improvement of symptoms, two had radiological improvement, and one had significant improvement of pulmonary function. Two patients whose pulmonary symptoms, function, and chest radiographs had deteriorated on penicillamine improved when treated with methotrexate. Methotrexate may be a useful treatment for fibrosing alveolitis complicating connective tissue diseases.

Fibrosing alveolitis is a well-recognised complication of rheumatoid arthritis, polymyositis, and other connective tissue diseases. It is difficult to treat and carries a poor prognosis. ${ }^{1}$ Conventional treatment with corticosteroids has been disappointing but more recent reports of immunosuppressive therapy, including azathioprine and cyclophosphamide, have been more encouraging. We have treated three patients with intramuscular methotrexate and report our findings.

\section{Methods}

Three patients with fibrosing alveolitis complicating connective tissue diseases were studied before and during methotrexate treatment. They were followed for a period ranging from 11 months to two years. Clinical assessments, chest radiographs, and pulmonary function tests were carried out before and at regular intervals during treatment. A diagnosis of fibrosing alveolitis was based on breathlessness, persistent late inspiratory basal crackles, typical chest radiographic appearances, and restrictive lung function tests with reduced gas transfer. Methotrexate was chosen initially because of an encouraging response of lung function when it was used to treat a case of polymyositis (see case 1). One other patient had rheumatoid arthritis and one dermatomyositis/scleroderma overlap syndrome. Details are recorded in the table.

Methotrexate was given by weekly intramuscular injections. A test dose of $5 \mathrm{mg}$ was followed by $20 \mathrm{mg}$ one week later. Thereafter the dose was titrated to balance maximum clinical benefit with minimal side effects. This

Table Clinical details and lung function studies-response to methotrexate

\begin{tabular}{|c|c|c|c|c|c|c|c|c|c|}
\hline & Diagnosis & Symptoms & $\begin{array}{l}\text { Chest } \\
\text { radiograph }\end{array}$ & $\begin{array}{l}\text { Time } \\
\text { of test } \\
\text { (months) }\end{array}$ & $\begin{array}{l}\text { FVC } \\
(\% \text { predicted }) \\
(I)\end{array}$ & $\begin{array}{l}\text { Volume } \\
\text { inspired } \\
(l)\end{array}$ & $\begin{array}{l}\text { TLCo } \\
(\% \text { predicted }) \\
(\mathrm{mmol} / \mathrm{min} / \mathrm{kPa})\end{array}$ & $\begin{array}{l}H b \\
(g / d l)\end{array}$ & $\begin{array}{l}\text { TLCo corrected } \\
\text { for Hb } \\
(\mathrm{mmol} / \mathrm{min} / \mathrm{kPa})\end{array}$ \\
\hline $\begin{array}{l}\text { NG } \\
\text { (Case 1) }\end{array}$ & $\begin{array}{l}\text { Rheumatoid/ } \\
\text { polymyositis }\end{array}$ & Improved & No change & $\begin{array}{r}0 \\
+\quad 9 \\
+15 \\
+22 \\
+23 \\
+27\end{array}$ & $\begin{array}{l}1.9(75) \\
1.9 \quad(75) \\
2.2 \quad(87) \\
1.7 \quad(66) \\
1.7 \quad(66) \\
2.05(80)\end{array}$ & $\begin{array}{l}1.6 \\
1.6 \\
2.0 \\
1.6 \\
1.6 \\
1.8\end{array}$ & $\begin{array}{l}3.35(45) \\
3.63(49) \\
4.04(54) \\
2.50(35) \\
2.50(35) \\
3.00(42)\end{array}$ & $\begin{array}{l}11 \cdot 8 \\
12 \cdot 3 \\
12 \cdot 4 \\
11 \cdot 0 \\
11 \cdot 1 \\
11 \cdot 0\end{array}$ & $\begin{array}{l}2 \cdot 21 \\
2 \cdot 3.9 \\
2.66 \\
1.66 \\
1.66 \\
2.00\end{array}$ \\
\hline $\begin{array}{l}\text { DH } \\
\text { (Case 2) }\end{array}$ & $\begin{array}{l}\text { Dermatomyositis/ } \\
\text { scleroderma }\end{array}$ & $\begin{array}{l}\text { Much } \\
\text { improved }\end{array}$ & $\begin{array}{l}\text { Much } \\
\text { improved }\end{array}$ & $\begin{array}{l}+1 \\
+7 \\
+13 \\
+19\end{array}$ & $\begin{array}{l}3 \cdot 55(74) \\
4 \cdot 15(87) \\
4 \cdot 25(89) \\
4 \cdot 65(97)\end{array}$ & $\begin{array}{l}\text { NR } 1 \\
\text { NR } \\
\text { NR } \\
\text { NR }\end{array}$ & $\begin{array}{l}3.04(29) \\
5.33(50) \\
6.58(63) \\
6.93(67)\end{array}$ & $\begin{array}{l}13 \cdot 9 \\
14 \cdot 0 \\
15 \cdot 3 \\
13 \cdot 7\end{array}$ & $\begin{array}{l}1 \cdot 98 \\
3 \cdot 47 \\
4 \cdot 26 \\
4 \cdot 52\end{array}$ \\
\hline $\begin{array}{l}\text { EL } \\
\text { (Case 3) }\end{array}$ & Rheumatoid & Improved & $\begin{array}{l}\text { Much } \\
\text { improved }\end{array}$ & $\begin{array}{l}-1 \\
+4 \\
+11\end{array}$ & $\begin{array}{l}2 \cdot 35(69) \\
2 \cdot 25(66) \\
2 \cdot 50(73)\end{array}$ & $\begin{array}{l}1 \cdot 8 \\
2 \cdot 0 \\
2 \cdot 3\end{array}$ & $\begin{array}{l}4.06(57) \\
4.91(69) \\
4.45(62)\end{array}$ & $\begin{array}{r}10 \cdot 1 \\
9 \cdot 4 \\
10 \cdot 4\end{array}$ & $\begin{array}{l}2 \cdot 72 \\
3 \cdot 31 \\
3 \cdot 01\end{array}$ \\
\hline
\end{tabular}

1 Inspired volume not recorded (NR) in case 2 during gas transfer. Resparameter was set at $10 \%$ below FVC for each TLCO measurement. 
resulted in a maintenance dose of $20 \mathrm{mg}$ per week in two patients and $30 \mathrm{mg}$ per week in the third.

Clinical assessment was carried out at routine outpatient appointments, and the degree of breathlessness and the presence, severity, and distribution of crackles were recorded. Serial chest radiographs were taken and were read at the end of the study by an independent radiologist without knowledge of the treatment or clinical response. Pulmonary function tests were performed at regular intervals. Forced vital capacity (FVC) and forced expiratory volume in one second $\left(\mathrm{FEV}_{1}\right)$ were measured on a vitalograph. The tracings were recorded in triplicate and the highest result was accepted and corrected for age and height to obtain a figure representing the percentage of predicted normal. The carbon monoxide transfer (TLCO) was measured by the single breath method on a PK Morgan resparameter mark IV. Measurements were repeated until two consecutive readings varied by less than $0.5 \mathrm{mmol} / \mathrm{min} / \mathrm{kPa}$. Results were corrected for age and height and a percentage of predicted normal obtained. The inspired volume during the single breath method was recorded in two patients. The resparameter was set to operate only if the inspired volume reached greater than FVC$10 \%$ FVC in the other patient (case 2). Tuco was corrected for haemoglobin concentration using the formula suggested by Cotes. ${ }^{2}$ Changes in TLCO or FVC of more than $20 \%$ of original values were considered clinically significant. Regular full blood counts and liver function tests were performed.

\section{Case reports}

CASE 1

This 64-year-old waitress (NG) had a history of nodular seropositive RA dating from 1972 . She first complained of breathlessness in 1974, and fibrosing alveolitis was confirmed by typical inspiratory crackles, chest radiographic changes, and restrictive lung function tests with impaired gas transfer (TLCO $5.03 \mathrm{mmol} / \mathrm{min} / \mathrm{kPa}$ $-64 \%$ predicted). Sjögren's syndrome was also noted. In April 1975 penicillamine (600 mg/day) was started for her arthritis. This was associated with improvement of her arthritis but deterioration of her pulmonary symptoms, and the penicillamine was discontinued in March 1976. Three months later she became severely ill with an acute polymyositis, manifested by weight loss, muscle weakness, wasting, and tenderness and confirmed by raised muscle enzymes and typical electromyographic and muscle biopsy changes. Pulmonary symptoms were still present, crackles marked at both bases, chest radiographs un- $-\overline{0}$ changed, and lung function tests showed further尺 deterioration (TLCO $3.35 \mathrm{mmol} / \mathrm{min} / \mathrm{kPa}-44 \% \%$ predicted). Treatment was started with metho- $\rightarrow$ trexate $\left(20 \mathrm{mg}\right.$ per week) with improvement of ${ }_{-}^{\circ}$ muscle power and function. An increase in dose $\vec{\omega}$ to $40 \mathrm{mg}$ per week caused severe oral candidiasis and the drug was stopped. Myositic symptoms recurred and muscle enzymes rose but thesect immediately responded to restarting her metho- trexate (fig 1). However, weight loss continued to? be a problem and prednisolone, $10 \mathrm{mg}$ per day, N was added with good effect. Apart from twoo episodes of pneumonia, progress was maintained ${ }_{-}^{\supset}$ and in January 1978 she had no respiratory or $\vec{O}$ myositic symptoms. Pulmonary function had also improved (TLCO $4.04 \mathrm{mmol} / \mathrm{min} / \mathrm{kPa}-54 \%$ 응 predicted). A temporary reduction in her methotrexate dose to $20 \mathrm{mg}$ alternate weeks was $\overrightarrow{0}$ followed by deterioration in pulmonary functiono (TLCo $2.52 \mathrm{mmol} / \mathrm{min} / \mathrm{kPa}-35 \%$ predicted) and some months later by an increase in muscle s enzyme levels but no muscle or pulmonary symptoms developed. Four months after increas-aे ing her methotrexate again her enzyme levels fello to normal. Pulmonary function tests again improved (TLCo $2.98 \mathrm{mmol} / \mathrm{min} / \mathrm{kPa}-42 \%$ pre-⿳⺈⿴囗十一 dicted). She has no pulmonary symptoms, but persistent basal crackles and her chest radiograph remains unchanged. Her present treatment is with prednisolone, $7 \cdot 5 \mathrm{mg}$ per day and methotrexate, $\overrightarrow{\vec{\partial}}$ $20 \mathrm{mg}$ weekly.

CASE 2
A 39-year-old man (DH) had a six-month

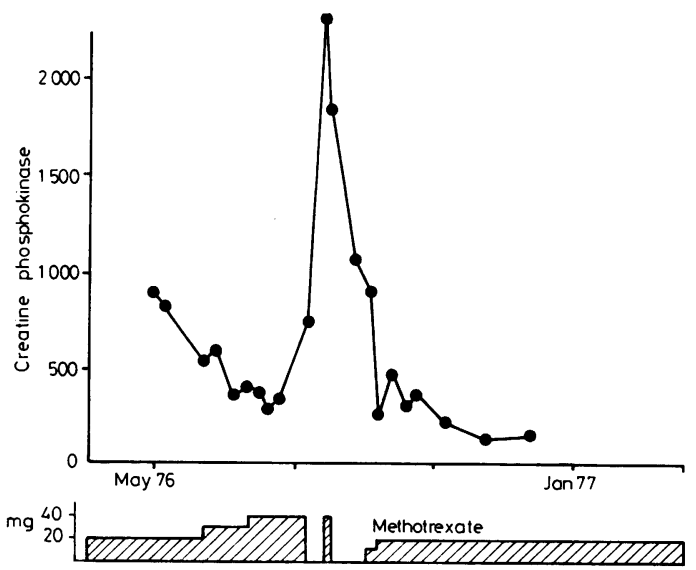

Fig 1 Patient 1. Response of creatine phosphokinase to stopping and restarting methotrexate. 
history of intermittent fever, malaise, polyarthropathy, weight loss, rash, and dyspnoea requiring frequent admissions to his local hospital. Investigations failed to elicit a diagnosis but revealed a persistently raised ESR, reticular basal shadowing on chest radiograph, and restrictive lung function tests with impaired gas transfer (TlCo $4.65 \mathrm{mmol} / \mathrm{min} / \mathrm{kPa}-44 \%$ predicted). Treatment with large doses of prednisolone (60 $\mathrm{mg}$ per day) and azathioprine had little effect. He was referred to Bath in February 1977, taking prednisolone $30 \mathrm{mg}$ per day and azathioprine $150 \mathrm{mg}$ per day. Examination revealed a severely ill man with pyrexia, obvious weight loss, muscle wasting, and breathlessness at rest. $\mathrm{He}$ had a generalised macular erythematous rash, violaceous discoloration on the backs of his knuckles, digital vasculitis, and sclerodactyly. Widespread inspiratory crackles were heard on auscultation of his chest. Apart from a persistently raised ESR (50 to $100 \mathrm{~mm}$ per hour), investigations were normal including renal and liver function, muscle enzymes, electromyography, nerve conduction, and negative autoantibodies (including antinuclear factor). Muscle biopsy showed no evidence of vasculitis or myositis. Chest radiograph confirmed basal shadowing and lung function tests showed a restrictive defect with further impairment of gas transfer (TLCO 3.05 $\mathrm{mmol} / \mathrm{min} / \mathrm{kPa}-29 \%$ predicted). A clinical diagnosis of dermatomyositis/scleroderma overlap syndrome was made. Despite continuation of corticosteroids and azathioprine his condition deteriorated and azathioprine was changed to methotrexate $30 \mathrm{mg}$ weekly. This led to steady improvement with weight gain, improving muscle power and respiratory symptoms, and clearing of the vasculitis despite lowering the dose of prednisolone. This progress has been maintained and by February 1978 his prednisolone had been discontinued, chest radiograph was normal (fig 2), and he had no breathlessness. Fine inspiratory crackles were restricted to the bases. Lung function had also improved (TLCo $6.59 \mathrm{mmol} /$ $\mathrm{min} / \mathrm{kPa}-64 \%$ predicted) and he was able to return to work. He remains well and methotrexate has recently been discontinued.

\section{CASE 3}

A 62-year-old matron (EL) developed seropositive nodular rheumatoid arthritis in 1974. A chest radiograph taken in 1975 showed nodular shadowing in both upper zones and irregular reticular basal shadowing. Serial radiographs failed to show any progression of the upper zone nodules which were, therefore, presumed to be

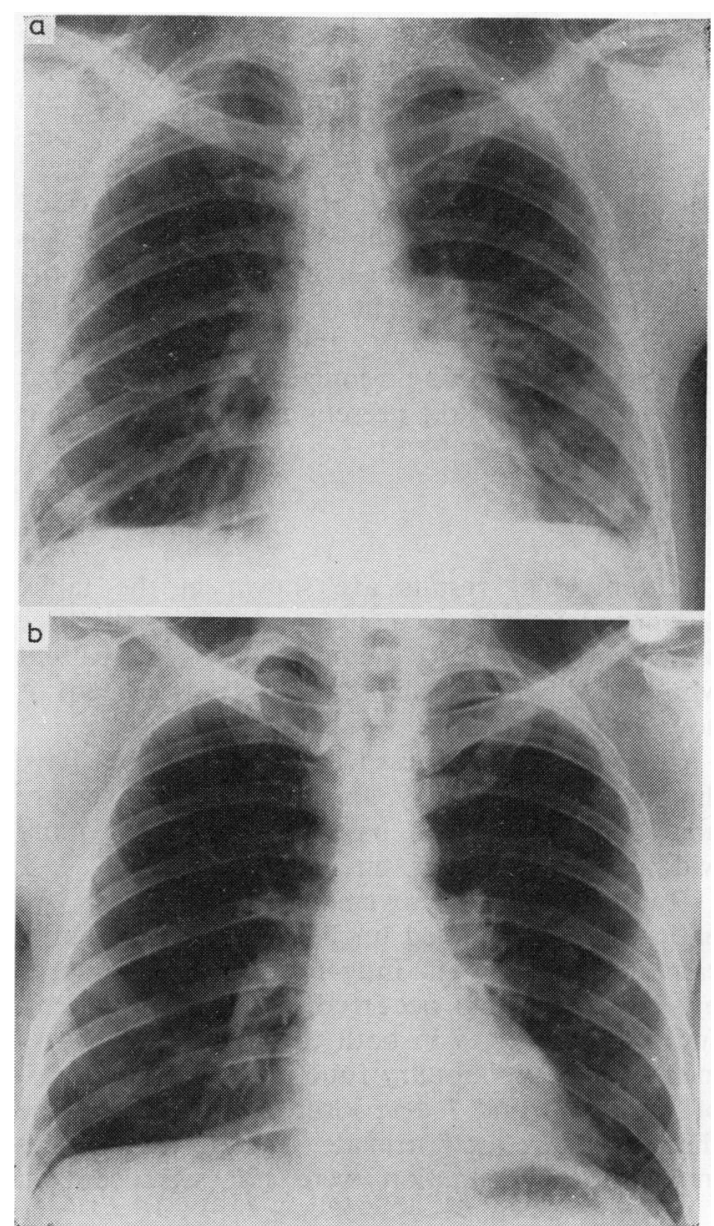

Fig 2 Patient 2. Chest radiographs before (a) and after (b) methotrexate showing clearing of basal shadowing.

rheumatoid. She first complained of mild breathlessness in January 1976, and lung function tests showed a restrictive defect in lung function with impaired gas transfer (TLCo $4.92 \mathrm{mmol} / \mathrm{min} / \mathrm{kPa}$ $-68 \%$ predicted). Other investigations included a positive latex test (DAT 1 in 128), anti-nuclear factor $640 \mathrm{IU}$, but negative DNA binding, and a markedly raised plasma viscosity $(2 \cdot 84 \mathrm{cp})$. Coexistent Sjögren's syndrome and Raynaud's phenomenon were noted. In May 1976 she had a left basal pneumonia which responded to appropriate antibiotic therapy but left her with some further dyspnoea. D-penicillamine therapy (500 mg per day), was associated with remission of her arthritis but her respiratory symptoms and function deteriorated (TLCO $4.06 \mathrm{mmol} / \mathrm{min} / \mathrm{kPa}$ $-52 \%$ predicted) and treatment was stopped in 
July 1977. Methotrexate, $25 \mathrm{mg}$ per week was started in August and resulted in a slow but steady improvement of pulmonary symptoms and function (TLCO $4.91 \mathrm{mmol} / \mathrm{min} / \mathrm{kPa}-69 \%$ predicted) by December. Previously noted basal crackles lessened and chest radiographs showed clearing at the bases (fig 3). Methotrexate was used intermittently between February and July 1978 because of recurrent chest infections, which responded to antibiotics, and then discontinued as breathlessness was no longer a problem. Upper lobe nodules are still present and her arthritis is quiescent.

\section{Results}

The individual results are shown in the table. Symptomatic improvement occurred in all three patients treated with methotrexate. One patient who was breathless at rest before treatment is now symptom-free.

Crackles are still present in all patients but have diminished in intensity. In patient 2 crackles are now confined to the bases, having been more widespread before treatment.

Radiographic improvement occurred in two patients and remained unchanged in one. Significant improvement in lung function as measured by FVC and TLCO occurred in only one patient. Individual changes in both these tests are shown in fig 4. The pulmonary function (and symptoms) of patients 1 and 3 deteriorated on penicillamine therapy before methotrexate. Though the changes in pulmonary function were not significant in these patients, the initial alteration in the downward trend of TLCo is shown clearly in fig 4 음 Patient 1 was treated with small doses of predni $\frac{\bar{s}}{\frac{1}{6}}$ solone which may have contributed to this im $\mathbb{D}$ provement. She also showed deterioration in pulmonary function after 15 months on methotrexate but with some subsequent recovery. This may have been caused by a mild respiratory infection at the time of measurement or by the reduction in dose. Patient 2 showed deterioration $\vec{x}$ in pulmonary function despite treatment withw large doses of corticosteriods and azathioprine but significant improvement with methotrexate. As his FVC also improved, Kco values were recorded and are shown in fig 4. The improvement in $\mathrm{KcO}$ was less dramatic than that in TLco but stilP significant. Kco values for patients 1 and $\overrightarrow{3}$ followed the same pattern as the TLCo showing op downward trend before treatment followed byo initial improvement. As with the Tlco values, these Kco changes were not significant.

Methotrexate caused severe oral candidiasis ing one patient, which responded promptly to dose reduction. Two patients developed pneumonias which were of bacterial origin and not associate of with neutropenia. There was no suggestion of drug-induced pneumonitis and no hepatotoxicity

\section{Discussion}

Fibrosing alveolitis describes a pathologica response in the lung without implying causation:Some aetiological agents are recognised but in most cases the primary cause remains unknown

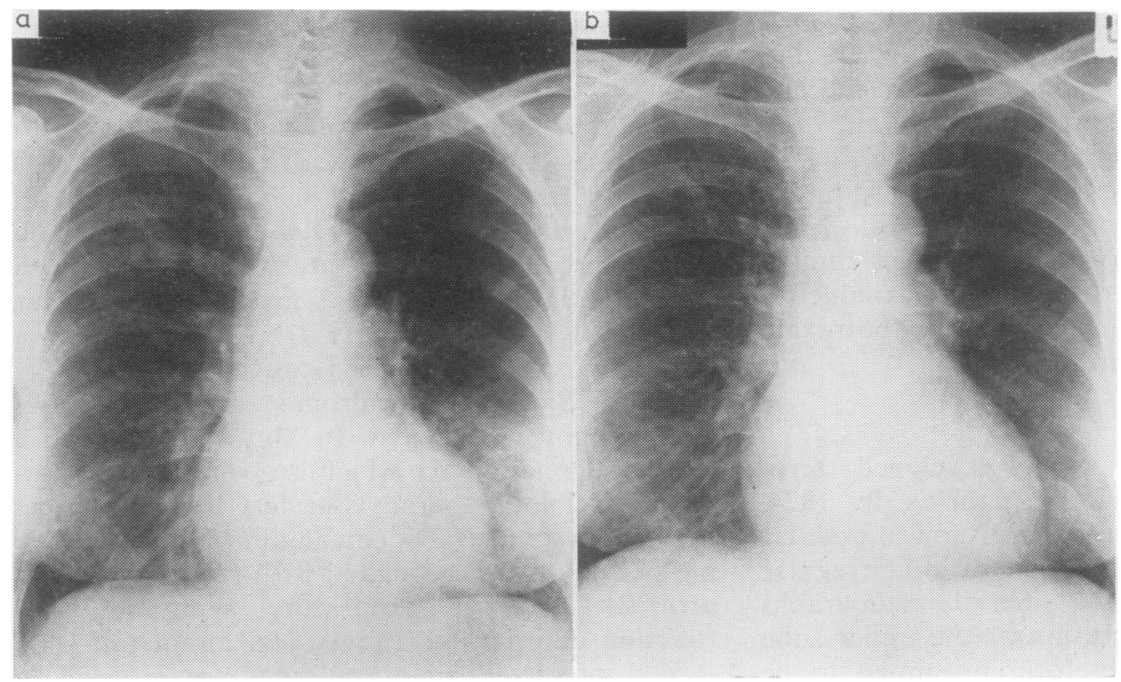

Fig 3 Patient 3. Chesto radiographs before (a) $\mathrm{\omega}$ and after (b) methotrexate showing clearing of basal changes. 


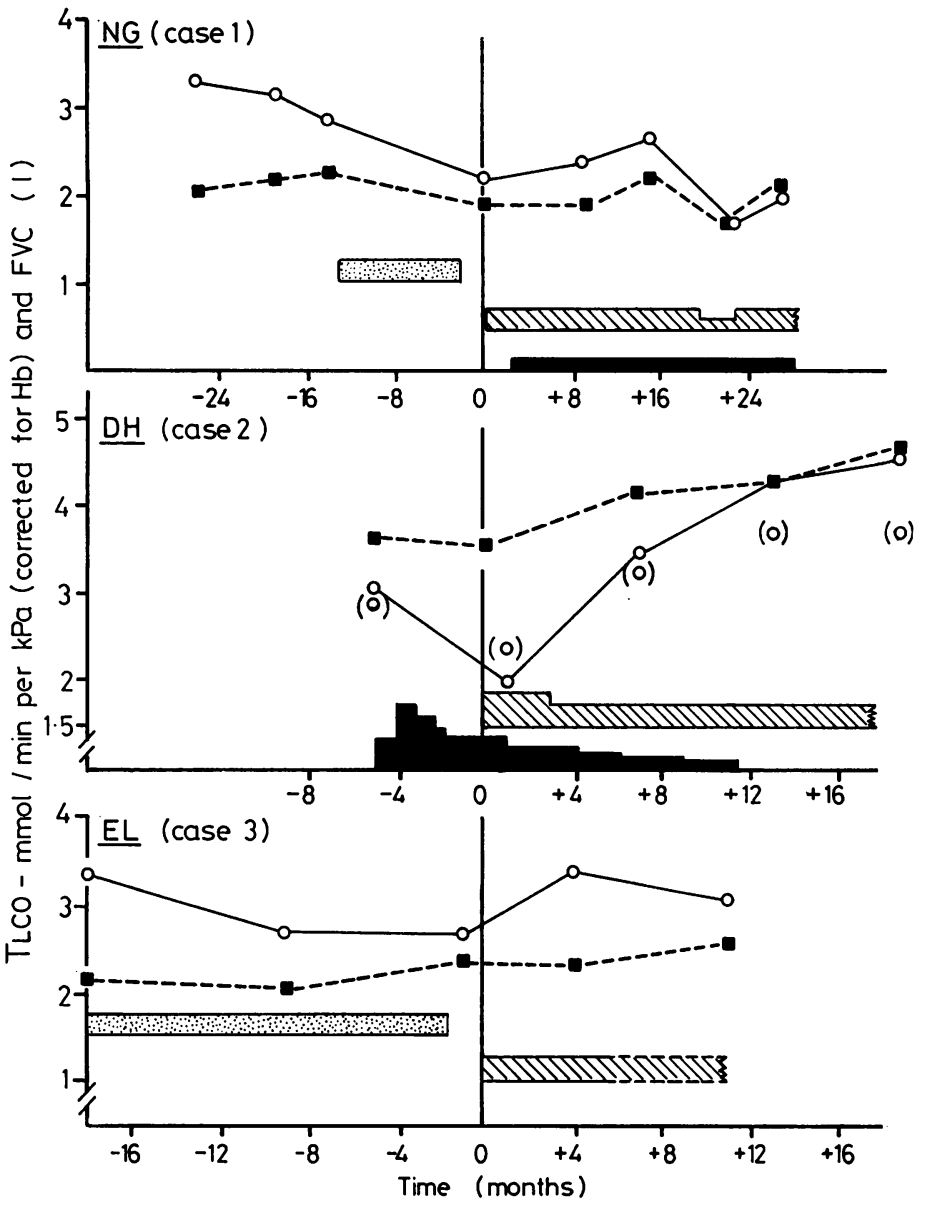

Fig 4 Effect of methotrexate therapy on forced vital capacity and gas transfer factor in the three patients. Note deterioration in both tests while on penicillamine before treatment with methotrexate in two of the patients. TLCO in $\mathrm{mmol} / \mathrm{min} / \mathrm{kPa}$ corrected for $\mathrm{Hb}(\mathrm{O}-\mathrm{O})$ and $\mathrm{FVC}$ in $l(\square-. \square) . D P E N=D$-penicillamine, $M T X=$ methotrexate, $P R E D=$ prednisolone. KCO $((O))$ shown for patient 2.
DPEN
MTX WWWUD
PRED

It occurs in association with connective tissue diseases and some patients with cryptogenic fibrosing alveolitis carry immunological markers of these disorders such as rheumatoid factor and antinuclear antibody. ${ }^{3}$ The importance of immunological mechanisms in aetiology is suggested by the presence of immunoglobulin and sometimes complement along alveolar walls and capillaries, and the presence in the blood of immune complexes in patients with active interstitial disease. This has been found both in cryptogenic fibrosing alveolitis ${ }^{45}$ and that complicating rheumatoid arthritis. ${ }^{50}$

Progress from interstitial infiltration with inflammatory cells to terminal fibrosis is implicit in the many terms used to describe fibrosing alveolitis (diffuse interstitial pneumonitis, pul- monary fibrosis and so on). It is hardly surprising that patients with extensive fibrosis respond less well to treatment than those with earlier active inflammatory changes. Prognosis and response to treatment are said to be improved in patients with prominent desquamation of alveolar cells rather than the more usual interstitial inflammatory infiltration. ${ }^{7}$ They are also better in younger patients $^{1}$ and those with a shorter history of lung disease. ${ }^{8}$ Those with evidence of circulating immune complexes respond better to treatment with corticosteriods. ${ }^{4}$ A more practical approach has been to assess the response to corticosteriods (the currently described treatment of choice), in order to avoid the procedure of lung biopsy except in patients with atypical features and where the diagnosis is in some doubt. ${ }^{9}$ Patients 
who respond to a trial of corticosteroids have a better prognosis, presumably because they have the more active early disease and possibly circulating complexes. Patient 2 had failed to respond to corticosteroids or to azathioprine and, therefore, had a poor prognosis yet he made the best response to methotrexate. Patients 1 and 3 had not been treated with corticosteroids. However they were both elderly with longstanding lung disease and had deteriorated both on no treatment and with penicillamine.

The overall prognosis is poor with a mean duration of observed lung disease less than five years before death. ${ }^{1}$ Corticosteroid treatment results in a useful response only in a minority of cases, ${ }^{1}$ and occasionally rapid deterioration may follow the start of such treatment. ${ }^{10}$ This and the immunological findings described above have led to the increasing use of immunosuppressive agents, such as azathioprine and cyclophosphamide. A selectively beneficial effect from azathioprine when used in conjunction with corticosteroids was found in a group of patients with "diffuse interstitial pneumonitis" over a mean period of 30 months. The responders had less fibrosis on biopsy. ${ }^{8}$ Cyclophosphamide has also been used with benefit in patients with fibrosing alveolitis resistant to corticosteroid therapy ${ }^{11}$ and in dermatomyositis with fibrosing alveolitis. ${ }^{12}$

Immunosuppressant agents have been used to treat patients with polymyositis and dermatomyositis, especially in those cases unresponsive to corticosteroids. Of the agents tried, methotrexate was found to be beneficial ${ }^{1314}$ and to be successful when other agents had failed. ${ }^{15}$ The only report of its use in fibrosing alveolitis complicating polymyositis was in terminal cases where it was without benefit. ${ }^{16} \mathrm{D}$-penicillamine is a widely used drug in the treatment of rheumatoid disease. We have treated nine patients with fibrosing alveolitis complicating rheumatoid arthritis with improvement of their arthritis but not of lung function.

We have been impressed by the symptomatic improvement in the patients treated with methotrexate. Two cases had deteriorated so badly that clinically the treatment appeared to have been lifesaving. Pulmonary function tests have been disappointing with little significant change in two patients despite clinical, and in one radiographic improvement. The changes in FVC which paralleled those of TLCO to some degree in patients 1 and 2 may relate directly to the physical effort required to perform pulmonary function tests adequately. These patients had clinical evidence of myositis and so interpretation of changes in lung function is difficult. Significant improvement in TLCo and Kco in patient 2 does, $\bar{C}$ however, suggest a real improvement in alveolar function.

Intermittent injections of methotrexate have been used to reduce the incidence of hepato toxicity ${ }^{15}$ and it is hoped that other complications 5 may also be reduced. Pneumonitis is a rare com plication which must be avoided in patients withw already impaired lung function but most reports? are of patients on oral therapy of more than $x$ $20 \mathrm{mg}$ per week. ${ }^{15}{ }^{17}$ Methotrexate appears $\omega$ promising addition to the treatment of fibrosing alveolitis.

We should like to thank the technicians for carrying out pulmonary function tests, $\mathrm{Dr} G$ Evison for reading chest radiographs, and Dr ARO Tanser and Dr G Laszlo for helpful advice.

\section{References}

1 Turner-Warwick M, Evans RC. Pulmonary mani $\stackrel{\infty}{\circ}$ festations of RA. In: Bluestone R, Bacon PA, (eds). Clinics in Rheumatic Diseases Vol 3, No 3.0 New York, WB Saunders, 1977: 3:549-64.

2 Cotes JE. Lung function assessment and applica tion in medicine. Oxford: Blackwell Scientifico Publications, 1975: 254-5.

3 Turner-Warwick M. Cryptogenic fibrosing alveo $\vec{\Rightarrow}$ litis. Br J Hosp Med 1972; 7:697-704.

4 Dreisin RB, Schwarz MI, Theofilopoulos AN, Stanford RE. Circulating immune complexes in the idiopathic interstitial pneumonias. $N$ Engl $\stackrel{\circ}{\circ}$ Med 1978; 298:353-7.

5 Haslam PL et al. Circulating immune complexes in patients with cryptogenic fibrosing alveolitis $x$ Clin Exp Immunol 1979; 37:381-90.

6 Dehoratius RJ, Abruzzo JL, Williams RC: Immunofluorescent and immunologic studies of rheumatoid lung. Arch Intern Med 1972; 129: 441-6.

7 Carrington CB, Gaensler EA, Coutu RE, Fitzgerald MX, Gupta RJ. Natural history ando treated course of usual and desquamative interstitial pneumonia. N Engl J Med 1978; 298:801-9 N

8 Winterbauer RH et al. Diffuse interstitial pneu monitis. Am J Med 1978; 65:661-72.

9 Editorial: Interstitial pneumonia (fibrosing alveo $N$ litis). Lancet 1978; 2:191-2.

10 Dixon A St J, Ball J. Honeycomb lung ando chronic rheumatoid arthritis: a case report. Annर्ष Rheum Dis 1957; 16:241.

11 Weese WC, Levine WB, Kazemi H. Interstitia lung disease resistant to corticosteroid therapy Report of three cases treated with azathioprines or cyclophosphamide. Chest 1975; 67:57-60.

12 Plowman PM, Stableforth DE. Dermatomyositis with fibrosing alveolitis: response to treatment with cyclophosphamide. Proc $R$ Soc Med 1977; 70:738-40. 
13 Sokaloff MC, Goldberg LS, Pearson CM. Treatment of corticosteroid resistant polymyositis with methotrexate. Lancet 1971; 1:14-6.

14 Arnett FC, Whelton JC, Zizic TM, Stevens MB. Methotrexate therapy in polymyositis. $A n n$ Rheum Dis 1973; 32:536-46.

15 Metzger AL, Bohan A, Goldberg AS, Bluestone $\mathbf{R}$, Pearson CM. Polymyositis and dermatomyositis: combined methotrexate and corticosteroid therapy. Ann Intern Med 1974; 81:182-9.

16 Schwarz MI, Matthay RA, Sahn SA, Stanford RE, Marmorstein BL. Scheinhorn DJ. Interstitial lung disease in polymyositis and dermatomyositis: analysis of six cases and review of the literature. Medicine 1976; 55:89-104.

17 Whitcomb ME, Schwarz MI, Tormey DC. Methotrexate pneumonitis: case report and review of the literature. Thorax 1972: 27:636-9. 